\title{
Rebamipide ophthalmic solution modulates the ratio of $T$ helper cell 17/regulatory $T$ cells in dry eye disease mice
}

\author{
RONGRONG FU ${ }^{1,2}$, YANHUA JIANG ${ }^{2}$, JING ZHOU $^{2}$ and JINSONG ZHANG ${ }^{1}$ \\ ${ }^{1}$ Department of Ophthalmology, The Fourth Affiliated Hospital of China Medical University, Shenyang, Liaoning 110032; \\ ${ }^{2}$ Department of Ophthalmology, Shenyang Fourth People's Hospital, Shenyang, Liaoning 110031, P.R. China
}

Received July 9, 2018; Accepted September 15, 2018

DOI: $10.3892 / \mathrm{mmr} .2019 .10068$

\begin{abstract}
The aim of the present study was to confirm the effect of $2 \%$ rebamipide ophthalmic solution on a scopolamine-induced dry eye (DE) mouse model, and to investigate its effect on the ratio of $\mathrm{T}$ helper cell 17 (Th17)/regulatory T cell (Treg) numbers. C57BL/6 mice received subcutaneous injections of scopolamine and were exposed to a low-humidity environment in order to establish a DE model. Rebamipide eye drops (2\%) administered four times daily for 2 weeks, significantly reduced the corneal staining scores and increased the tear film breakup time and tear production in the DE mice. Pathologically, the rebamipide restored the histological changes induced by DE in the cornea, conjunctiva and lacrimal gland. At a molecular level, it downregulated pro-inflammatory and upregulated anti-inflammatory cytokines in the conjunctiva and lacrimal gland. Furthermore, the increased Th17 and Treg levels were restored following treatment with rebamipide. In conclusion, the anti-inflammatory and Th17/Treg balance-preserving effects of rebamipide may contribute to the treatment of DE in mice.
\end{abstract}

\section{Introduction}

Dry eye (DE), a common ophthalmic disorder, is defined as a multifactorial disease of the tears and ocular surface that results in symptoms of discomfort, visual disturbance, and tear film instability with potential damage to the ocular surface. It is accompanied by increased osmolarity of the tear film and inflammation of the ocular surface (1). DE may be induced by a number of causes, including aging, excessive computer use, contact lenses usage, androgen deficiency, medication and air pollution (2). Worldwide, 5-30\% of the population suffer

Correspondence to: Dr Jinsong Zhang, Department of Ophthalmology, The Fourth Affiliated Hospital of China Medical University, 4 East Chongshan Road, Shenyang, Liaoning 110032, P.R. China

E-mail: zhangjins1234@163.com

Key words: dry eye, inflammation, rebamipide, Th17 cells, T-lymphocytes from DE (3). Although vision may not be adversely affected, DE causes various problems, including tearing, dryness and photophobia, leading to a measurable adverse impact on visual function and daily life $(4,5)$. If untreated, DE does not heal naturally and its symptoms persist. However, treatments for the improvement of the symptoms and signs may not cure the condition completely (6). Current DE treatments aim to attenuate the clinical symptoms and objective signs, and improve the life quality of patients.

Rebamipide ophthalmic solution was developed by Otsuka Pharmaceutical Co., Ltd. (Tokyo, Japan), and launched in Japan for the treatment of DE (Mucosta ${ }^{\circledR}$ ophthalmic suspension, unit dose $2 \%$ ). Rebamipide has been used as a therapeutic agent for gastritis and gastric ulcers due to its anti-inflammatory, antioxidant and gastric epithelial mucin-promoting effects (7-11). The use of rebamipide has been extended to DE treatment due to the discovery of its ocular surface mucin-increasing action. The compound was revealed to increase mucin-like substances on the cornea and conjunctiva of $\mathrm{N}$-acetylcysteine-treated rabbits (12). This outcome has been confirmed in vitro in cultured conjunctival goblet cells and corneal epithelial cells (13-16). In addition, rebamipide has been demonstrated to exert an anti-inflammatory response in ocular autoimmune lesions in a Sjogren's syndrome mouse model (17). In clinical studies, rebamipide has been demonstrated to be effective in improving the symptoms and signs of DE (18-20). It has also been demonstrated to be well tolerated in a 52-week trial (21). Studies over the past five years have further evaluated the action of rebamipide on various types of DE. Their results revealed that the regimen is effective in treating keratoconjunctivitis sicca in patients with Sjögren syndrome (22), chronic ocular graft-versus-host disease-associated DE and ocular cicatricial pemphigoid-like disease (23), and postoperative DE (24).

Regarding the pharmacological mechanisms of rebamipide in DE, the majority of studies have focused on mucin production. One previous study indicated that a T helper cell 17 (Th17)/T regulatory cell (Treg) imbalance occurs in DE, and interleukin (IL)-17 blockage reduces the severity of the disease, indicating that the measurement of the Th17/Treg ratio may have a diagnostic use in the treatment of DE (25). In the present study, the effects of rebamipide on the modulation of the Th17/Treg balance were evaluated, and possible novel mechanisms of action on rebamipide in DE treatment were investigated. 


\section{Materials and methods}

Animals. For the present study, a total of 40 female C57BL/6 mice (8-week-old, 20-22 g) obtained from the Experimental Animal Center of China Medical University (Shenyang, China) were housed in 50-60\% humidity and kept on a 12-h light/dark cycle at $22 \pm 2^{\circ} \mathrm{C}$ with free access to food and water. The experimental protocol was approved by the Animal Ethics Committee of The Fourth Affiliated Hospital of China Medical University.

Experimental procedure. DE was induced as described previously (26). Briefly, the mice were randomly divided into four groups: Control (con); DE model (DE); DE with balanced salt solution treatment (DE+vehicle); and $\mathrm{DE}$ with $2 \%$ rebamipide treatment (DE+Reb) ( $\mathrm{n}=10$ mice/group). The mice in the three DE groups were exposed to an environment of $<20 \%$ relative humidity, $21-23^{\circ} \mathrm{C}$ and airflow of $15 \mathrm{l} / \mathrm{min}$ for $16 \mathrm{~h} /$ day, and received subcutaneous injections of scopolamine hydrobromide $(0.5 \mathrm{mg} / 0.2 \mathrm{ml}$ resolved in saline; Dalian Meilun Biotech Co., Ltd., Dalian, China) at 8:00 a.m., 11:00 a.m., 2:00 p.m. and 5:00 p.m. daily for 2 weeks. The mice in the control group were placed in a normal environment without airflow and received subcutaneous injections of an equal volume of saline at the same time points. Following the establishment of the model, the mice in the DE+Reb group were treated with $2 \%$ rebamipide eye drops (Mucosta ${ }^{\circledR}$; Otsuka Pharmaceutical Co., Ltd.) four times daily for 2 weeks. The mice in the DE+vehicle group were treated with salt solution at the same time points.

Tear secretion and stability of tear film examinations. Tear secretion was evaluated using the phenol red thread test. The mice were fixed in a 50-ml tube with the bottom cut off and phenol red-impregnated cotton threads (Tianjin Jingming New Technological Development Co., Ltd., Tianjin, China) were applied to the lateral canthus for $15 \mathrm{sec}$. The length of wetting of the thread, which turned red, was measured (mm).

The stability of the tear film was examined using a tear film breakup time (BUT) assay and corneal fluorescein staining. The mice were anesthetized with $50 \mathrm{mg} / \mathrm{kg}$ pentobarbital sodium (intraperitoneal) and $1 \mu \mathrm{l} 1 \%$ fluorescein sodium (Alcon Laboratories, Inc., Duluth, GA, USA) were applied to the conjunctival sac. The BUT was recorded as the duration between the natural blink response of the mice to the appearance of a dark area, representing tear film breakup, using slit-lamp biomicroscopy and a cobalt blue light (BX900; Haag-Streit AG, Koeniz, Switzerland). The BUT was recorded three times and the average time was used. Then excess fluorescein sodium was rinsed using PBS and the corneal epithelium deficit was evaluated using fluorescein punctate staining the duration of which depended on the natural blink response time of each mouse. The staining was scored according to previously established standards (27).

Histological examination. From each group, six mice were randomly selected for histological examination. Following rebamipide administration, the mice were sacrificed by deep anesthesia and the cornea and lacrimal gland were collected and fixed in $10 \%$ neutral formalin at $4^{\circ} \mathrm{C}$ for $24 \mathrm{~h}$. The fixed samples were embedded in optimal cutting temperature (OCT) medium and cut into 8- $\mu \mathrm{m}$-thick cryosections. The sections were stained with hematoxylin for $5 \mathrm{~min}$ and eosin for $3 \mathrm{~min}$ at room temperature. The histological alterations in the cornea and lacrimal gland were observed under a light microscope at x400 or x200 magnification (DP73; Olympus Corporation, Tokyo, Japan).

ELISA. ELISA was used to measure the levels of IL-1 $\beta$, IL-6, tumor necrosis factor- $\alpha$ (TNF- $\alpha$ ), IL-10, IL-17, and IL-23 in the conjunctiva and lacrimal gland. The tissues were homogenized in PBS at $4^{\circ} \mathrm{C}$ and subjected to three freeze-thaw cycles. The homogenates were centrifugated at $10,000 \mathrm{x} \mathrm{g}$ at $4^{\circ} \mathrm{C}$ for $20 \mathrm{~min}$. The supernatant was collected for measurement. The measurements were performed using commercial ELISA kits [MultiSciences (Lianke) Biotech Co., Ltd., Hangzhou, China], according to the manufacturer's protocols. The catalog number of each kit was: IL-1ß: EK201B2/2; IL-6: EK2062/2; TNF- $\alpha$ : EK2822/2; IL-10: EK2102/2; IL-17: EK2172/2; IL-23: EK2232.

RNA isolation and reverse transcription-quantitative polymerase chain reaction ( $R T-q P C R)$. Total RNA was isolated from the conjunctiva and lacrimal gland samples using the RNApure total RNA Fast Isolation kit (BioTeke Corporation, Beijing, China). The isolated RNA was quantified and reverse transcribed in a $20 \mu \mathrm{l}$ reaction system containing $1 \mu \mathrm{g}$ RNA sample, $1 \mu \mathrm{l}$ random primer, $2 \mu \mathrm{l}$ dNTP, $1 \mu 1$ oligo(dT) $)_{15}, 4 \mu 1$ 5XBuffer, $0.5 \mu 1$ RNasin and $1 \mu 1$ Moloney murine leukemia virus reverse transcriptase. Reverse transcription reactions were carried out at $42^{\circ} \mathrm{C}$ for $50 \mathrm{~min}$ and $95^{\circ} \mathrm{C}$ for $5 \mathrm{~min}$. RT-qPCR was performed using 2X Power Taq PCR Master Mix (BioTeke) and SYBR Green (Beijing Solarbio Science \& Technology Co., Ltd., Beijing, China) on an Exicycler 96 real-time PCR system (Bioneer Corporation, Daejeon, Korea). All reactions were incubated at $94^{\circ} \mathrm{C}$ for $10 \mathrm{~min}, 60^{\circ} \mathrm{C}$ for $20 \mathrm{sec}$, and $72^{\circ} \mathrm{C}$ for $30 \mathrm{sec}$, followed by 40 cycles of $72^{\circ} \mathrm{C}$ for $2 \mathrm{~min} 30 \mathrm{sec}, 40^{\circ} \mathrm{C}$ for $5 \mathrm{~min} 30 \mathrm{sec}$, $60^{\circ} \mathrm{C}$ for $30 \mathrm{sec}$, and $25^{\circ} \mathrm{C}$ for $1 \mathrm{~min}$. The primers used are listed in Table I. The relative expression of the genes was measured against $\beta$-actin and was calculated using the $2^{-\Delta \Delta \mathrm{Cq}}$ method (28).

Immunofluorescence staining. The fixed samples were embedded in OCT medium and cut into $10-\mu$ m-thick cryosections. The sections were boiled in a citrate buffer in a microwave oven for $10 \mathrm{~min}$ for antigen retrieval. Following blocking in $10 \%$ goat serum (Beijing Solarbio Science \& Technology Co., Ltd.) for $15 \mathrm{~min}$ at room temperature, the sections were incubated with anti-keratin 10 (K10; 1:50; cat. no. sc-53252), or anti-IL-17 (1:50; cat. no. sc-374218) (both Santa Cruz Biotechnology, Inc., Dallas, TX, USA) and anti-cluster of differentiation (CD)4 (1:100; cat. no. 19068-1-AP; Proteintech Group, Inc., Chicago, IL, USA) antibodies or with anti-forkhead box P3 (Foxp3; 1:50; cat. no. sc-53876; Santa Cruz Biotechnology, Inc.) and anti-CD4 (1:100) antibodies at $4^{\circ} \mathrm{C}$ overnight. Following washing, the sections were incubated with fluorescein isothiocyanate-conjugated goat/anti-mouse (1:200; A0568; Beyotime Institute of Biotechnology, Haimen, China) and Cy3-conjugated goat/anti-rabbit secondary antibodies (1:200; A0516; Beyotime Institute of Biotechnology) for 
Table I. Primer sequences for reverse transcription-quantitative polymerase chain reaction analysis

\begin{tabular}{lll}
\hline Genes & \multicolumn{1}{c}{ Upstream } & \multicolumn{1}{c}{ Downstream } \\
\hline IL-1 $\beta$ & 5'-TTGGGCCTCAAAGGAAAGAAT-3' & 5'-TGCTTGTGAGGTGCTGATGTA-3' \\
IL-6 & 5'-TGTATGAACAACGATGATGCAC-3' & 5'-CTGGCTTTGTCTTTCTTGTT-3' \\
TNF- $\alpha$ & 5'-GAGTCCGGGCAGGTCTACTT-3' & 5'-CCAGGTCACTGTCCCAGCATC-3' \\
IL-17 & 5'-TGTGTCTCTGATGCTGTTGCT-3' & 5'-TTCATTGCGGTGGAGAGTC-3' \\
IL-23 & 5'-GCCTGCTCTACTCCCTGAT-3' & 5'-GTTGGCACTAAGGGCTCA-3' \\
IL-10 & 5'-GAAGACAATAACTGCACCCACT-3' & 5'-ACCCAAGTAACCCTTAAAGTCC-3' \\
$\beta$-actin & 5'-CTGTGCCCATCTACGAGGGCTAT-3' & 5'-TTTGATGTCACGCACGATTTCC-3'
\end{tabular}

IL, interleukin; TNF, tumor necrosis factor.

$60 \mathrm{~min}$ at room temperature. The staining was observed under a BX50 fluorescence microscope (Olympus Corporation) at x400 magnification.

Statistical analysis. The data are expressed as the mean \pm standard deviation. Experiments were repeated 6 or 10 times as described above. Groups were compared using one-way analysis of variance followed by Tukey's post hoc test for data with a normal distribution, and by Games-Howell analysis with Dunn's multiple comparisons test for skewed data using SPSS 19.0 software (IBM Corp., Armonk, NY, USA). $\mathrm{P}<0.05$ was considered to indicate a statistically significant difference.

\section{Results}

Rebamipide attenuates the symptoms of DE. The effects of rebamipide on the symptoms of DE were evaluated by the examination of corneal fluorescein staining, BUT and tear production. A total of 4 weeks after the model was established, the mean corneal fluorescein staining score was significantly increased in the DE group $(8.10 \pm 1.37)$ compared with the control group $(1.30 \pm 0.48)(\mathrm{P}<0.01)$. Vehicle treatment for 2 weeks did not affect the score $(7.90 \pm 1.37$; $\mathrm{P}>0.05$ vs. the control group). However, following 2 weeks of treatment with $2 \%$ rebamipide, the corneal fluorescein staining score decreased to $3.5 \pm 0.71$, which was significantly lower compared with that in the $\mathrm{DE}+$ vehicle group $(\mathrm{P}<0.01)$ (Fig. 1A and B).

Regarding the measurement of tear film BUT, the results revealed that the values taken from the DE group were significantly lower compared with those from the control group $(2.80 \pm 1.22$ vs. $12.70 \pm 1.42 ; \mathrm{P}<0.01)$, and rebamipide treatment partly restored this change $(5.70 \pm 1.16 ; \mathrm{P}<0.05$ vs. the DE+vehicle group) (Fig. 1C). In accordance with the results from the BUT measurement, the tear volume (represented as the wetting length of the phenol red thread) in the DE group was markedly reduced compared with the control group $(0.51 \pm 0.17$ vs. $4.50 \pm 0.29 ; \mathrm{P}<0.01)$, and rebamipide treatment slightly but significantly increased the tear production in DE mice $(0.93 \pm 0.17 ; \mathrm{P}<0.01$ vs. the $\mathrm{DE}+$ vehicle group). The tear production in the vehicle group demonstrated no statistically significant difference when compared with that in the DE group $(0.54 \pm 0.16 ; \mathrm{P}>0.05)$ (Fig. 1D).
Rebamipide attenuates the histological changes in the cornea and lacrimal glands in DE mice. Hematoxylin and eosin staining revealed that superficial epithelial cells in the corneas of the control mice were well arranged and tightly attached, and the surface of the cornea was smooth (Fig. 2A). However, the epithelial layers of the cornea were disrupted, and the epithelial cells were desquamated in the DE mice. In addition, the lacrimal glands in the control group exhibited a unbroken structure and uniform size of the acinus (Fig. 2B). In the DE mice, the lacrimal glands exhibited notable vacuolization and a disordered cellular arrangement. The vehicle did not affect the histological alterations in the lacrimal glands, whereas $2 \%$ rebamipide administration markedly attenuated these pathological alterations.

Rebamipide increases the density of goblet cells and decreases squamous metaplasia. In the conjunctival sections, the number of goblet cells was decreased in the DE mice compared with that in the control mice (Fig. 3). Rebamipide treatment significantly increased the number of goblet cells. Furthermore, epidermis-specific K10 expression was examined in the corneal epithelia. In the control group, few K10-positive epithelial cells were observed in the cornea, whereas DE induced a marked increase in the expression of K10, which is a hallmark of squamous metaplasia. Rebamipide treatment significantly weakened the intensity of K10 expression compared with that observed in the vehicle-treated group (Fig. 3).

Rebamipide modulates the production of inflammatoryassociated factors. To further investigate the alterations in inflammatory-associated factors following rebamipide treatment, the levels of known pro- and anti-inflammatory cytokines in the lacrimal gland and corneal tissues were determined. As demonstrated in Fig. 4, the mRNA expression levels and protein content of the pro-inflammatory cytokines IL-1 $\beta$, IL-6, TNF- $\alpha$, IL-17 and IL-23 were significantly enhanced, whereas the anti-inflammatory cytokine IL-10 was significantly decreased, in the samples from DE mice. Treatment with $2 \%$ rebamipide for 2 weeks markedly reversed these effects.

Rebamipide modulates Th17 differentiation in the ocular microenvironment of DE mice. To evaluate the impact of 
A

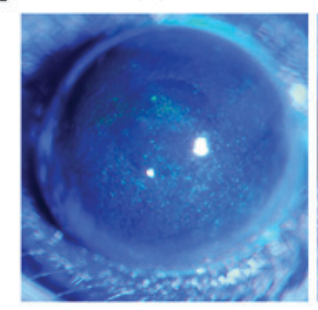

B

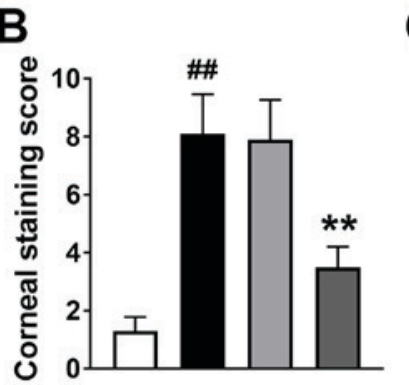

$\mathrm{DE}$

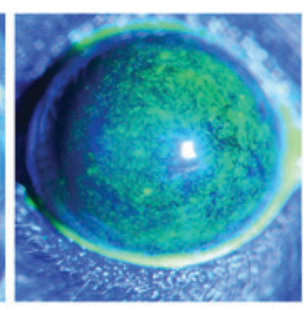

C

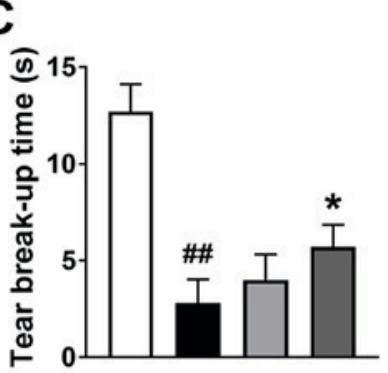

DE+vehicle

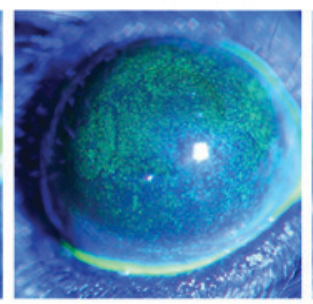

D

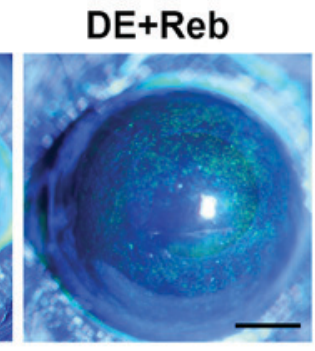

ㅁ con

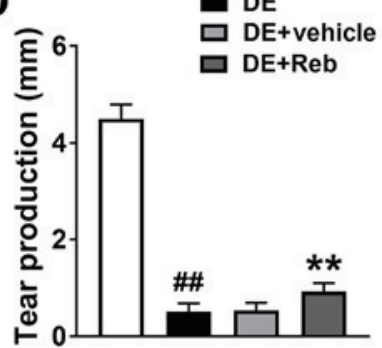

Figure 1. Rebamipide (2\%) improves the clinical symptoms of DE in mice. (A) Corneal fluorescein staining in the various groups of mice. Scale bar=1 mm. (B) Quantification of corneal fluorescein staining. (C) Tear film breakup time. (D) Tear production expressed as the length of wetting of the thread. The data are expressed as the mean \pm standard deviation $(\mathrm{n}=10) .{ }^{\# \#} \mathrm{P}<0.01$ vs. the control group; ${ }^{*} \mathrm{P}<0.05$ vs. the $\mathrm{DE}+\mathrm{vehicle}$ group; ${ }^{* *} \mathrm{P}<0.01 \mathrm{vs}$. the $\mathrm{DE}+\mathrm{vehicle}$ group. con, control; DE, dry eye, DE+vehicle, dry eye group treated with vehicle; DE+Reb, dry eye group treated with $2 \%$ rebamipide.

A

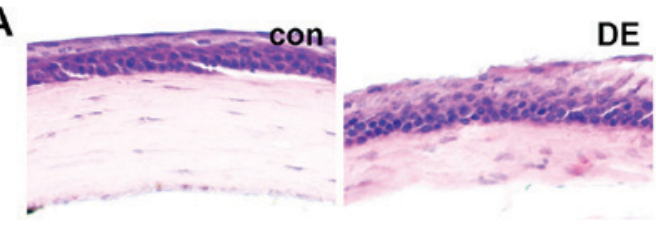

B

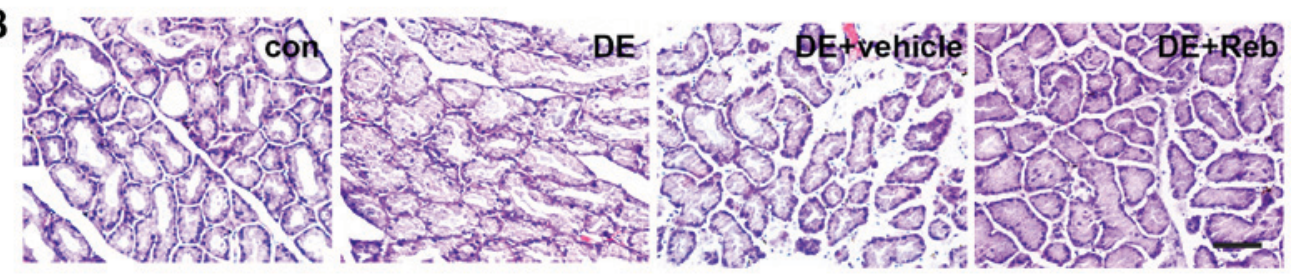

Figure 2. Rebamipide (2\%) attenuates the histological changes in the cornea and lacrimal glands in DE mice. Hematoxylin and eosin staining of (A) the cornea and (B) the lacrimal glands. Scale bars, 50 and $100 \mu \mathrm{m}$, respectively. con, control; DE, dry eye; DE+vehicle, dry eye group treated with vehicle; DE+Reb, dry eye group treated with $2 \%$ rebamipide.

rebamipide on the ratio of Th17 and Tregs in the ocular microenvironment, double-immunofluorescence was performed to locate $\mathrm{CD}^{+} / \mathrm{IL}-17^{+}$and $\mathrm{CD} 4^{+} / \mathrm{Foxp}^{+}$double-positive cells in the cornea and lacrimal gland. As demonstrated in Fig. 5, more $\mathrm{CD}^{+} / \mathrm{IL}-17^{+}$and $\mathrm{CD} 4+/$ Foxp $^{+}$cells were observed in the cornea and lacrimal gland specimens from the DE mice compared with those of the control, indicating that DE altered the ratio of Th17/Tregs in the ocular microenvironment. Treatment with rebamipide $(2 \%)$ led to decreases in the numbers of $\mathrm{CD}^{+} / \mathrm{IL}_{-} 17^{+}$cells and $\mathrm{CD} 4^{+} / \mathrm{Foxp}^{+}$cells.

\section{Discussion}

In the present study, the effect of $2 \%$ rebamipide on scopolamine-induced DE mice was confirmed. Rebamipide eye drops led to the restoration of corneal, conjunctival and lacrimal gland DE-induced alterations, and the regulation of the secretion of inflammatory cytokines. Furthermore, it was revealed that rebamipide modulated the Th17/Treg imbalance by suppressing Th17 cells and increasing the differentiation of Treg cells.

The tissue components that comprise the ocular surface are responsible for maintaining its integrity and function. The cornea is one of the most important tissues in the maintenance of visual function and microenvironment of ocular surface. The cornea consists of epithelial cells and keratocytes. The epithelial layer is directly exposed to the external environment, and the tightly arranged epithelial cells provide protection from exposure to pathogens. The corneal keratocytes are distributed in the stroma and maintain the extracellular matrix by synthesizing glycosaminoglycans and collagen. In DE, desiccation and excessive inflammation lead to corneal thinning and the reduction of superficial corneal epithelial microvilli $(29,30)$. In the present study, a relatively thin cornea and disordered epithelial and stromal layers were observed in DE mice. In addition, the epithelial cells were detached from 


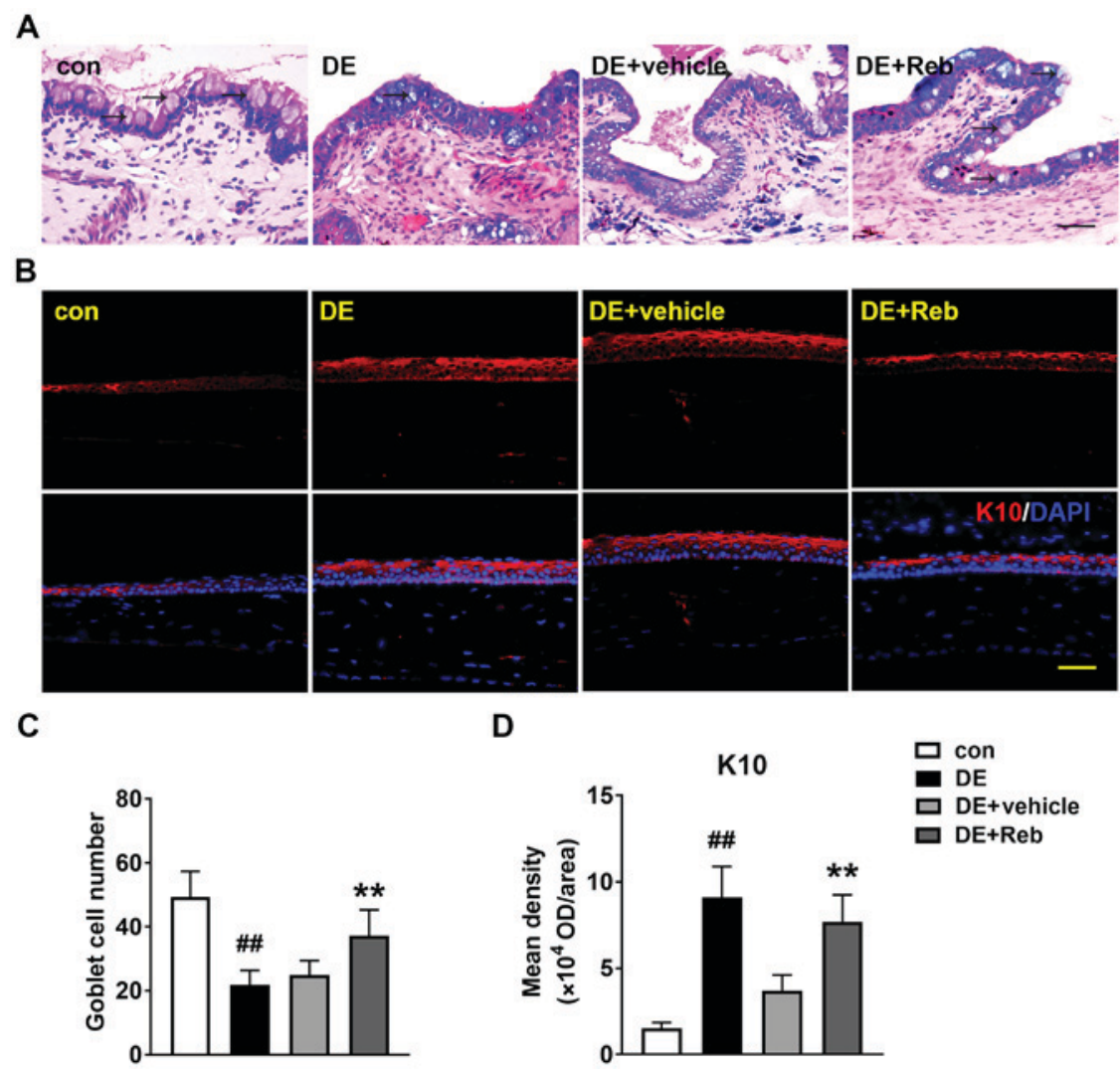

Figure 3. Rebamipide (2\%) increases the conjunctival goblet cell number and ameliorated the corneal epithelium squamous metaplasia. (A) Hematoxylin and eosin staining of the conjunctiva. (B) Immunofluorescence staining of K10 co-stained with DAPI. Scale bar, $50 \mu \mathrm{m}$. (C) Conjunctival goblet cell count based on the hematoxylin and eosin staining. (D) Quantification of the mean fluorescence density of the K10-positive area. $\mathrm{n}=6$. ${ }^{\# \#} \mathrm{P}<0.01 \mathrm{vs}$. the control group; ${ }^{* *} \mathrm{P}<0.01$ vs. the DE+vehicle group. K10, keratin 10; con, control; DE, dry eye; DE+vehicle, dry eye group treated with vehicle; DE+Reb, dry eye group treated with $2 \%$ rebamipide.
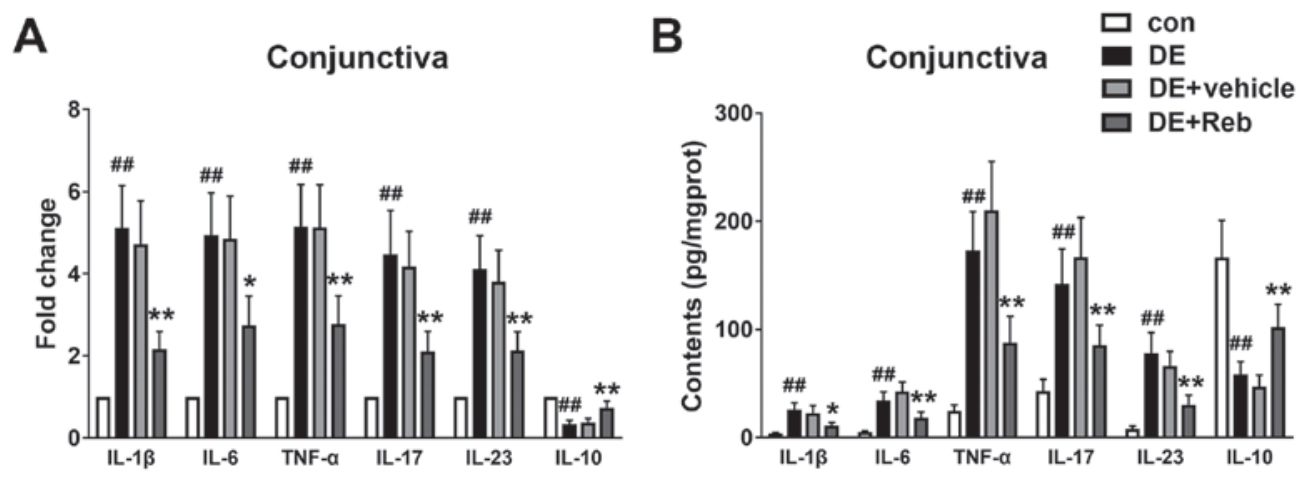

C

Lacrimal gland
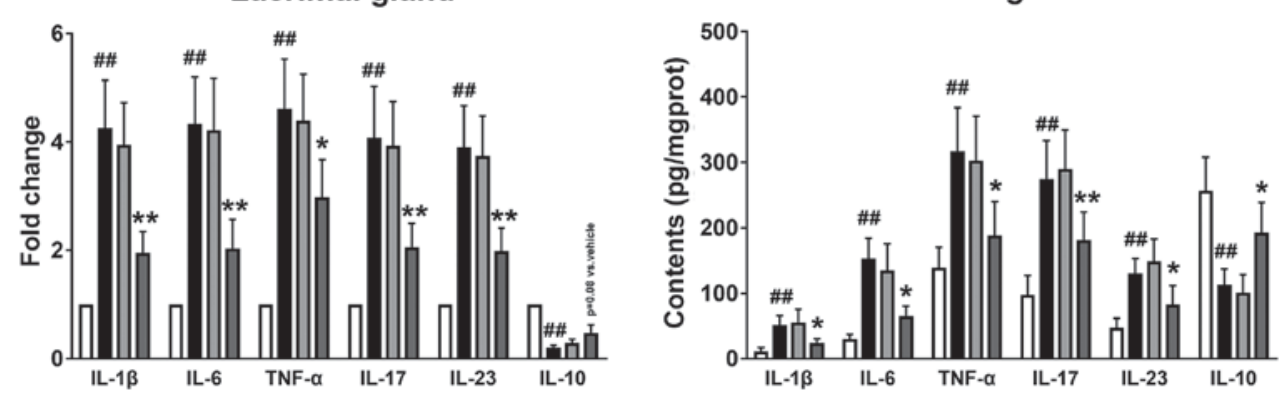

Figure 4. Anti-inflammatory effects of $2 \%$ rebamipide in the lacrimal gland and conjunctiva of DE mice. (A) mRNA and (B) protein expression levels of inflammatory cytokines in the conjunctiva. (C) mRNA and (D) protein expression levels of inflammatory cytokines in the lacrimal gland. The data are expressed as the mean \pm standard deviation $(\mathrm{n}=6) .{ }^{\# \#} \mathrm{P}<0.01$ vs. the control group; ${ }^{*} \mathrm{P}<0.05$ vs. the $\mathrm{DE}+\mathrm{vehicle}$ group; ${ }^{* *} \mathrm{P}<0.01$ vs. the $\mathrm{DE}+\mathrm{vehicle}$ group. con, control group; DE, dry eye; DE+vehicle, dry eye group treated with vehicle; DE+Reb, dry eye group treated with $2 \%$ rebamipide. 


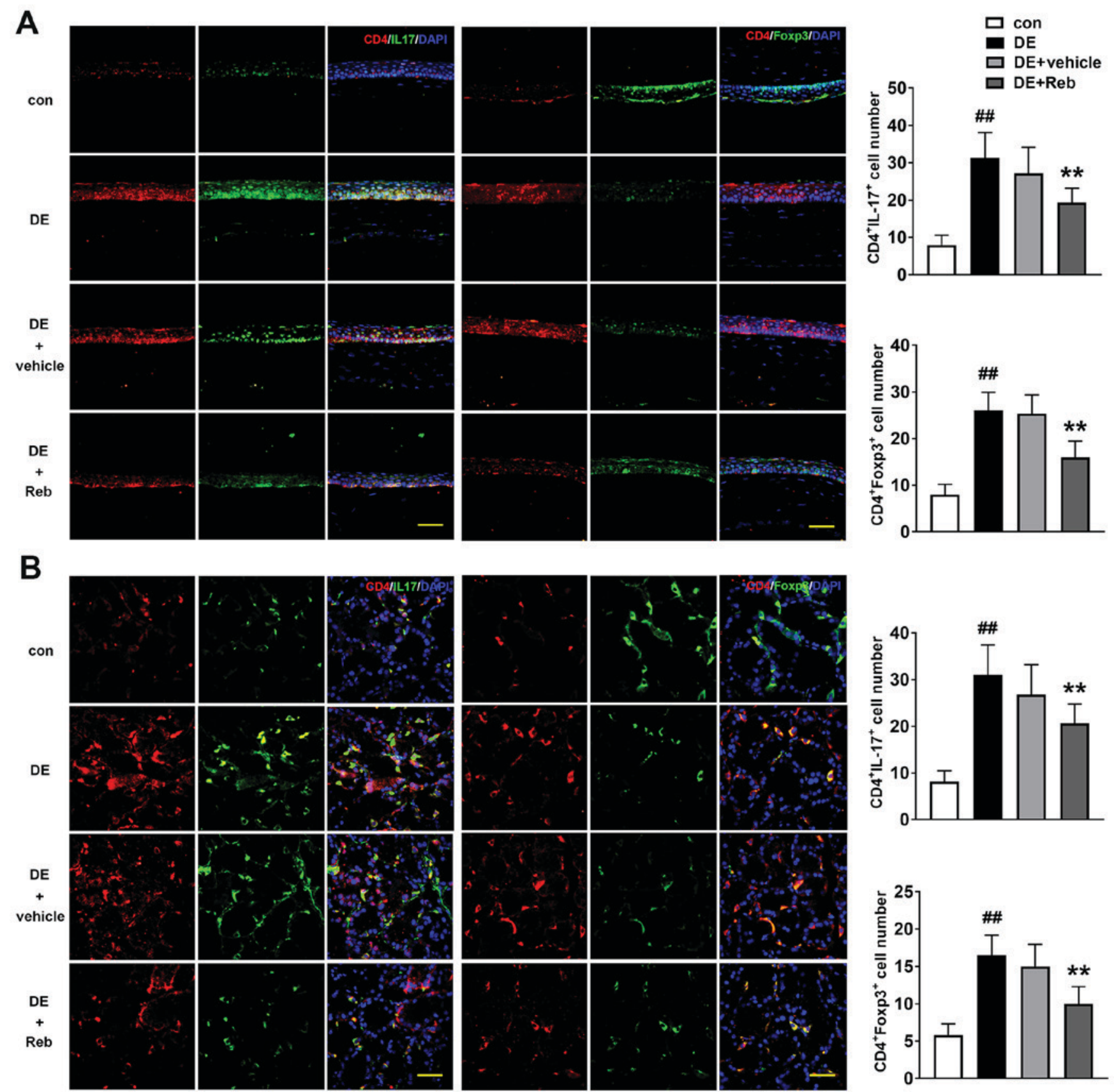

Figure 5. Regulatory effects of $2 \%$ rebamipide on the Th17/Treg ratio in DE mice. The presence of CD4 $4^{+} \mathrm{IL}-17^{+}$cells and CD4 $4^{+} \mathrm{Treg}^{+}$cells in (A) the cornea and (B) lacrimal gland was detected with double immunofluorescence staining. The red staining represents CD4 ${ }^{+}$and the green staining represents IL-17 ${ }^{+}$or Treg ${ }^{+}$. Nuclei were counterstained with DAPI (blue). Scale bar $=50 \mu \mathrm{m}$. Data are expressed as the mean \pm standard deviation $(\mathrm{n}=6)$. ${ }^{\# /} \mathrm{P}<0.01$ vs. the control group; ${ }^{* *} \mathrm{P}<0.01$ vs. the DE+vehicle group. Th17, T helper 17 cell; Treg, regulatory T cell; CD, cluster of differentiation; IL, interleukin; Foxp3, forkhead box P3; con, control; DE, dry eye; DE+vehicle, dry eye group treated with vehicle; DE+Reb, dry eye group treated with $2 \%$ rebamipide.

the ocular surface and marked squamous metaplasia occurred. These results indicated that DE induces damage to the cornea. Following treatment with $2 \%$ rebamipide, these impairments were attenuated, and the structure of the cornea was repaired.

The lacrimal gland is another key tissue that contributes to the hemostasis of the ocular surface. In its healthy state, the lacrimal gland secretes tears that contain electrolytes, soluble proteins and mucus. Normal tear secretion maintains the moisture of the ocular surface and serves as a light refraction medium in the eye. Furthermore, the lacrimal gland secretes microbicidal proteins, which suppress pathogenic invasion onto the ocular surface (31). In DE, lacrimal gland secretion is diminished due to the loss of acinar and ductal cells, induced by the neuroendocrine stimuli (32). In the scopolamine-induced DE mouse model used in the present study, markedly impaired acinar cells were observed and treatment with $2 \%$ rebamipide attenuated the damage. The rebamipide treatment also led to increased tear BUT and production, which may be associated with protection of the lacrimal gland. These results confirmed the beneficial effects of $2 \%$ rebamipide on DE and indicated that these actions may be associated with cornea and lacrimal gland protection.

$\mathrm{CD}^{+} \mathrm{T}$ cell-mediated inflammatory responses serve a key role in DE $(33,34)$. In the disease condition, the lacrimal 
functional unit, which is composed of the cornea, conjunctiva, lacrimal glands and meibomian glands (35), is vulnerable to pro-inflammatory cytokines (36). Various inflammatory markers have been discovered in the lacrimal gland and conjunctiva in different types of DE (37). These pro-inflammatory cytokines are able to inhibit neural activity and neurotransmitter release (38), and lead to goblet cell loss $(39,40)$. In the present study, treatment with $2 \%$ rebamipide was demonstrated to exert effective anti-inflammatory functions, as evidenced by the significant decrease in the production of the pro-inflammatory cytokines IL- $1 \beta$, IL- 6 and TNF- $\alpha$, and the increased production of the anti-inflammatory cytokine IL-10, in the lacrimal gland and conjunctiva. These observations are consistent with previous findings in the tear fluid of superoxide dismutase-1(-/-) mice (41) and in the conjunctival tissues of NFS/sld mice (17). These results suggest that treatment with $2 \%$ rebamipide has an anti-inflammatory effect on the conjunctiva and lacrimal glands of DE mice.

Th17 are a subset of $\mathrm{T}$ helper cells that secrete the inflammatory cytokine IL-17 (42). Transforming growth factor- $\beta 1$ (TGF- $\beta 1)$, IL-6, IL-21 and IL-23 are important for the differentiation of Th17 $(43,44)$. Increased levels of IL-17 have been demonstrated in the lacrimal and submandibular glands of Sjögren syndrome model mice $(45,46)$. IL-17 induces corneal epithelial barrier disruption in DE (47). The inhibition of IL-17 in various ways significantly decreases the severity of DE in animal models (48-50). Tregs, which are differentiated following TGF- $\beta$ stimulation, regulate the formation of pathogenic T cells, particularly Th17. The balance between Th17 and Tregs is important for maintaining immune responses. However, in DE, the function of Tregs is impaired and the Treg-induced suppression of Th17 is overcome (25). In the present study, $2 \%$ rebamipide effectively restored this equilibrium by suppressing the differentiation of Th17 cells and upregulating that of Tregs in the cornea and lacrimal gland. The result was in accordance with the previous study on curdlan-induced spondyloarthritis mice (51). The present data indicated that the regulation of the balance between Th17 and Tregs may contribute to the remedial action of $2 \%$ rebamipide in DE mice.

In conclusion, $2 \%$ rebamipide acts on the cornea and lacrimal glands in DE mice in a protective manner, which may be associated with its anti-inflammatory and Th17/Treg regulatory functions. The present study revealed a novel pharmacological mechanism of action of rebamipide in DE therapy and highlighted a potential novel anti-DE drug.

\section{Acknowledgements}

Not applicable.

\section{Funding}

No funding was received.

\section{Availability of data and materials}

The datasets used and/or analyzed during the current study are available from the corresponding author on reasonable request.

\section{Authors' contributions}

RF, YJ and JZho performed the experiments. RF and JZho acquired and analyzed the data. RF and JZho interpreted the data. RF drafted the manuscript. JZha designed the experiment and revised the manuscript.

\section{Ethics approval and consent to participate}

The experimental protocol was approved by the Animal Ethics Committee of The Fourth Affiliated Hospital of China Medical University.

\section{Patient consent for publication}

Not applicable.

\section{Competing interests}

The authors declare that they have no competing interests.

\section{References}

1. The definition and classification of dry eye disease: Report of the Definition and Classification Subcommittee of the International Dry Eye WorkShop (2007). Ocul Surf 5: 75-92, 2007.

2. Marshall LL and Roach JM: Treatment of dry eye disease. Consult Pharm 31: 96-106, 2016.

3. No authors listed: The epidemiology of dry eye disease: Report of the Epidemiology Subcommittee of the International Dry Eye WorkShop (2007). Ocul Surf 5: 93-107, 2007.

4. Rapoport Y, Singer JM, Ling JD, Gregory A and Kohanim S: A comprehensive review of sex disparities in symptoms, pathophysiology, and epidemiology of dry eye syndrome. Semin Ophthalmol 31: 325-336, 2016.

5. Miljanović B, Dana R, Sullivan DA and Schaumberg DA: Impact of dry eye syndrome on vision-related quality of life. Am J Ophthalmol 143: 409-415, 2007.

6. American Academy of Ophthalmology Cornea/External Disease Panel: Dry Eye Syndrome Preferred Practive Pattern Guidelines. American Academy of Ophthalmology, San Francisco, CA, 2013.

7. Arakawa T, Higuchi K, Fujiwara Y, Watanabe T, Tominaga K, Sasaki E, Oshitani N, Yoshikawa T and Tarnawski AS: 15th anniversary of rebamipide: Looking ahead to the new mechanisms and new applications. Dig Dis Sci 50 (Suppl 1): S3-S11, 2005.

8. Higuchi K, Arakawa T, Nebiki H, Uchida T, Fujiwara Y, Ando K, Yamasaki K, Takaishi O, Fukuda T, Kobayashi K and Kuroki T: Rebamipide prevents recurrence of gastric ulcers without affecting Helicobacter pylori status. Dig Dis Sci 43: 99S-106S, 1998.

9. Yamasaki K, Kanbe T, Chijiwa T, Ishiyama $\mathrm{H}$ and Morita S: Gastric mucosal protection by OPC-12759, a novel antiulcer compound, in the rat. Eur J Pharmacol 142: 23-29, 1987.

10. Yoshikawa T, Naito Y, Tanigawa T and Kondo M: Free radical scavenging activity of the novel anti-ulcer agent rebamipide studied by electron spin resonance. Arzneimittelforschung 43: 363-366, 1993.

11. Naito Y, Yoshikawa T, Tanigawa T, Sakurai K, Yamasaki K, Uchida $\mathrm{M}$ and Kondo M: Hydroxyl radical scavenging by rebamipide and related compounds: Electron paramagnetic resonance study. Free Radic Biol Med 18: 117-123, 1995

12. Urashima H, Okamoto T, Takeji Y, Shinohara H and Fujisawa S: Rebamipide increases the amount of mucin-like substances on the conjunctiva and cornea in the $\mathrm{N}$-acetylcysteine-treated in vivo model. Cornea 23: 613-619, 2004.

13. Rios JD, Shatos M, Urashima H, Tran H and Dartt DA: OPC-12759 increases proliferation of cultured rat conjunctival goblet cells. Cornea 25: 573-581, 2006.

14. Rios JD, Shatos MA, Urashima H and Dartt DA: Effect of OPC-12759 on EGF receptor activation, p44/p42 MAPK activity, and secretion in conjunctival goblet cells. Exp Eye Res 86: 629-636, 2008 
15. Takeji Y, Urashima H, Aoki A and Shinohara H: Rebamipide increases the mucin-like glycoprotein production in corneal epithelial cells. J Ocul Pharmacol Ther 28: 259-263, 2012.

16. Itoh S, Itoh $\mathrm{K}$ and Shinohara $\mathrm{H}$ : Regulation of human corneal epithelial mucins by rebamipide. Curr Eye Res 39: 133-141, 2014

17. Arakaki R, Eguchi H, Yamada A, Kudo Y, Iwasa A, Enkhmaa T, Hotta F, Mitamura-Aizawa S, Mitamura Y, Hayashi Y, et al: Anti-inflammatory effects of rebamipide eyedrop administration on ocular lesions in a murine model of primary Sjögren's syndrome. PLoS One 9: e98390, 2014.

18. Kinoshita S, Awamura S, Oshiden K, Nakamichi N, Suzuki H and Yokoi N; Rebamipide Ophthalmic Suspension Phase II Study Group: Rebamipide (OPC-12759) in the treatment of dry eye: A randomized, double-masked, multicenter, placebo-controlled phase II study. Ophthalmology 119: 2471-2478, 2012.

19. Kinoshita S, Oshiden K, Awamura S, Suzuki H, Nakamichi N and Yokoi N; Rebamipide Ophthalmic Suspension Phase 3 Study Group: A randomized, multicenter phase 3 study comparing $2 \%$ rebamipide (OPC-12759) with $0.1 \%$ sodium hyaluronate in the treatment of dry eye. Ophthalmology 120: 1158-1165, 2013.

20. Koh S, Inoue Y, Sugmimoto T, Maeda N and Nishida K: Effect of rebamipide ophthalmic suspension on optical quality in the short break-up time type of dry eye. Cornea 32: 1219-1223, 2013

21. Kinoshita S, Awamura S, Nakamichi N, Suzuki H, Oshiden K and Yokoi N; Rebamipide Ophthalmic Suspension Long-term Study Group: A multicenter, open-label, 52-week study of $2 \%$ rebamipide (OPC-12759) ophthalmic suspension in patients with dry eye. Am J Ophthalmol 157: 576-583.e1, 2014.

22. Arimoto A, Kitagawa K, Mita N, Takahashi Y, Shibuya E and Sasaki H: Effect of rebamipide ophthalmic suspension on signs and symptoms of keratoconjunctivitis sicca in Sjögren syndrome patients with or without punctal occlusions. Cornea 33: 806-811, 2014.

23. Yamane M, Ogawa Y,Fukui M, Kamoi M, Saijo-Ban Y, Yaguchi S, Mukai S, Kawakita T, Simmura S and Tsubota K: Long-term rebamipide and diquafosol in two cases of immune-mediated dry eye. Optom Vis Sci 92: S25-S32, 2015.

24. Kato K, Miyake K, Kondo N, Asano S, Takeda J, Takahashi A, Takashima Y and Kondo M: Conjunctival goblet cell density following cataract surgery with diclofenac versus diclofenac and rebamipide: A randomized trial. Am J Ophthalmol 181: 26-36, 2017.

25. Chauhan SK, El Annan J, Ecoiffier T, Goyal S, Zhang Q, Saban DR and Dana R: Autoimmunity in dry eye is due to resistance of Th17 to Treg suppression. J Immunol 182: 1247-1252, 2009.

26. Barabino S, Shen L, Chen L, Rashid S, Rolando M and Dana MR: The controlled-environment chamber: A new mouse model of dry eye. Invest Ophthalmol Vis Sci 46: 2766-2771, 2005.

27. Zhang C, Li K, Yang Z, Wang Y and Si H: The effect of the aqueous extract of Bidens pilosa $\mathrm{L}$. on androgen deficiency dry eye in rats. Cell Physiol Biochem 39: 266-277, 2016.

28. Livak KJ and Schmittgen TD: Analysis of relative gene expression data using real-time quantitative PCR and the 2(-Delta Delta C(T)) method. Methods 25: 402-408, 2001.

29. Sanchis-Gimeno JA, Lleó-Pérez A, Alonso L, Rahhal MS and Martínez-Soriano F: Reduced corneal thickness values in postmenopausal women with dry eye. Cornea 24: 39-44, 2005.

30. Fabiani C, Barabino S, Rashid S and Dana MR: Corneal epithelial proliferation and thickness in a mouse model of dry eye. Exp Eye Res 89: 166-171, 2009.

31. Garg A and Zhang X: Lacrimal gland development: From signaling interactions to regenerative medicine. Dev Dyn 246: 970-980, 2017.

32. Sullivan DA: Sex hormones and Sjögren's syndrome. J Rheumatol (Suppl 50): S17-S32, 1997.

33. Stern ME and Pflugfelder SC: Inflammation in dry eye. Ocul Surf 2: 124-130, 2004.

34. Stern ME, Siemasko KF, Gao J, Calonge M, Niederkorn JY and Pflugfelder SC: Evaluation of ocular surface inflammation in the presence of dry eye and allergic conjunctival disease. Ocul Surf 3: S161-S164, 2005.
35. Stern ME, Beuerman RW, Fox RI, Gao J, Mircheff AK and Pflugfelder SC: The pathology of dry eye: The interaction between the ocular surface and lacrimal glands. Cornea 17: 584-589, 1998.

36. Stern ME, Gao J, Siemasko KF, Beuerman RW and Pflugfelder SC: The role of the lacrimal functional unit in the pathophysiology of dry eye. Exp Eye Res 78: 409-416, 2004.

37. Pflugfelder SC, Corrales RM and de Paiva CS: T helper cytokines in dry eye disease. Exp Eye Res 117: 118-125, 2013.

38. Song XJ, Li DQ, Farley W, Luo LH, Heuckeroth RO, Milbrandt J and Pflugfelder SC: Neurturin-deficient mice develop dry eye and keratoconjunctivitis sicca. Invest Ophthalmol Vis Sci 44: 4223-4229, 2003.

39. Zhang X, Chen W, De Paiva CS, Corrales RM, Volpe EA, McClellan AJ, Farley WJ, Li DQ and Pflugfelder SC: Interferon- $\gamma$ exacerbates dry eye-induced apoptosis in conjunctiva through dual apoptotic pathways. Invest Ophthalmol Vis Sci 52: 6279-6285, 2011

40. de Paiva CS, Schwartz CE, Gjörstrup P and Pflugfelder SC: Resolvin E1 (RX-10001) reduces corneal epithelial barrier disruption and protects against goblet cell loss in a murine model of dry eye. Cornea 31: 1299-1303, 2012.

41. Ohguchi T, Kojima T, Ibrahim OM, Nagata T, Shimizu T, Shirasawa T, Kawakita T, Satake Y, Tsubota K, Shimazaki J, et al: The effects of $2 \%$ rebamipide ophthalmic solution on the tear functions and ocular surface of the superoxide dismutase-1 (sod1) knockout mice. Invest Ophthalmol Vis Sci 54: 7793-7802, 2013.

42. Bettelli E, Oukka M and Kuchroo VK: T(H)-17 cells in the circle of immunity and autoimmunity. Nat Immunol 8: 345-350, 2007.

43. Cooke A: Th17 cells in inflammatory conditions. Rev Diabet Stud 3: 72-75, 2006

44. Bettelli E, Carrier Y, Gao W, Korn T, Strom TB, Oukka M, Weiner HL and Kuchroo VK: Reciprocal developmental pathways for the generation of pathogenic effector TH17 and regulatory T cells. Nature 441: 235-238, 2006.

45. De Paiva CS, Hwang CS, Pitcher JD III, Pangelinan SB Rahimy E, Chen W, Yoon KC, Farley WJ, Niederkorn JY, Stern ME, et al: Age-related T-cell cytokine profile parallels corneal disease severity in Sjögren's syndrome-like keratoconjunctivitis sicca in CD25KO mice. Rheumatology (Oxford) 49: 246-258, 2010.

46. Pitcher JD III, De Paiva CS, Pelegrino FS, McClellan AJ, Raince JK, Pangelinan SB, Rahimy E, Farley WJ, Stern ME, Li DQ, et al: Pharmacological cholinergic blockade stimulates inflammatory cytokine production and lymphocytic infiltration in the mouse lacrimal gland. Invest Ophthalmol Vis Sci 52: 3221-3227, 2011.

47. De Paiva CS, Chotikavanich S, Pangelinan SB, Pitcher JD III, Fang B, Zheng X, Ma P, Farley WJ, Siemasko KF, Niederkorn JY, et al: IL-17 disrupts corneal barrier following desiccating stress. Mucosal Immunol 2: 243-253, 2009.

48. Dohlman TH, Chauhan SK, Kodati S, Hua J, Chen Y, Omoto M, Sadrai Z and Dana R: The CCR6/CCL20 axis mediates Th17 cell migration to the ocular surface in dry eye disease. Invest Ophthalmol Vis Sci 54: 4081-4091, 2013.

49. Zhang X, Volpe EA, Gandhi NB, Schaumburg CS, Siemasko KF, Pangelinan SB, Kelly SD, Hayday AC, Li DQ, Stern ME, et al: NK cells promote Th-17 mediated corneal barrier disruption in dry eye. PLoS One 7: e36822, 2012.

50. Sadrai Z, Stevenson W, Okanobo A, Chen Y, Dohlman TH, Hua J, Amparo F, Chauhan SK and Dana R: PDE4 inhibition suppresses IL-17-associated immunity in dry eye disease. Invest Ophthalmol Vis Sci 53: 3584-3591, 2012.

51. Min HK, Kim JK, Lee SY, Kim EK, Lee SH, Lee J, Kwok SK, Cho ML and Park SH: Rebamipide prevents peripheral arthritis and intestinal inflammation by reciprocally regulating Th17/Treg cell imbalance in mice with curdlan-induced spondyloarthritis. J Transl Med 14: 190, 2016.

c) (i) $\Theta$ This work is licensed under a Creative Commons Attribution-NonCommercial-NoDerivatives 4.0 International (CC BY-NC-ND 4.0) License. 